\begin{tabular}{cc|c}
\hline Tar. Bil. Der. & Journal of Agricultural Sciences \\
& $\begin{array}{c}\text { Dergi web sayfası: } \\
\text { www.agri.ankara.edu.tr/dergi }\end{array}$ & Journal homepage: \\
& www.agri.ankara.edu.tr/journal
\end{tabular}

\title{
Tokat İli Turhal İlçesinde Sığır Besiciliğinde Üretim Maliyeti ve Canlı Ağırlık Artışına Etki Eden Faktörler
}

\author{
Bilge GÖZENER ${ }^{\mathrm{a}}$, Murat SAYILI ${ }^{\mathrm{b}}$ \\ ${ }^{a}$ Gaziosmanpaşa Üniversitesi, Ziraat Fakültesi, Tarım Ekonomisi Bölümü, Taşlıçiftlik Yerleşkesi, 60240, Tokat, TÜRKiYE \\ ${ }^{b}$ Gaziosmanpaşa Üniversitesi, İktisadi ve İdari Bilimler Fakültesi, İşletme Bölümü, Taşllç̧ftlik Yerleşkesi, 60240, Tokat, TÜRKIYYE
}

\section{ESER BILGISII}

Araştırma Makalesi

DOI: 10.1501/Tarimbil_0000001331

Sorumlu Yazar: Bilge GÖZENER, E-posta: bilge.gozener@gop.edu.tr, Tel: +90 (356) 2521616 / 2266

Geliş Tarihi: 24 Ocak 2014, Düzeltmelerin Gelişi: 13 Haziran 2014, Kabul: 23 Temmuz 2014

\begin{abstract}
ÖZET
Bu araştırmada, Tokat İli Turhal İlçesinde sığır besiciliği yapan işletmelerin üretim maliyetleri ile sığır besiciliğinde canlı ağırlık artışı ve buna etki eden faktörler tespit edilmiştir. Araştırmada kullanılan veriler, bölgede sığır besiciliği yapan 68 adet işletmeden anket yoluyla elde edilmiştir. Örnek hacminin tespitinde Basit Tesadüfî Örnekleme Yöntemi kullanılmıştır. Araştırma sonucunda, işletmelerin ortalama 27.91 baş yerli irk, 32.50 baş melez ırk ve 18.00 baş kültür ırkı hayvan ile besicilik yaptıkları belirlenmiştir. Besi sonucunda elde edilen canlı ağırlık artışının $285.65 \mathrm{~kg}$ baş$^{-1}$ ile kültür ırkı hayvanlarda en yüksek olduğu, yemden en iyi yararlanan ırkın yine kültür ırkı hayvanlar olduğu belirlenmiştir. Üretim masrafları içerisinde en yüksek paya hayvan materyali ve yem giderleri sahiptir. 1 baş hayvanın besi sonu maliyeti; yerli ırklarda 1779.72 TL, melez ırklarda 1877.06 TL ve kültür ırklarında 2384.59 TL'dir. Regresyon analizi sonucuna göre, işletmeler daha düşük canlı ağırlığa sahip daha fazla hayvan ile besicilik yaptığında, toplamda daha fazla canlı ağırlık elde edebilirler.
\end{abstract}

Anahtar Kelimeler: Besi süresi; Canlı ağırlık artışı; Regresyon analizi; Sığır besiciliği; Turhal ilçesi

\section{Production Cost and Factors Affecting Live Weight Gain in Cattle Fattening in the Turhal District of Tokat Province}

\section{ARTICLE INFO}

Research Article

Corresponding Author: Bilge GÖZENER, E-mail: bilge.gozener@gop.edu.tr, Tel: +90 (356) 2521616 / 2266

Received: 24 January 2014, Received in Revised Form: 13 June 2014, Accepted: 23 July 2014

\begin{abstract}
In this study, production costs and profitability of cattle fattening farms in Turhal district of Tokat province have been determined. In addition, the factors affecting live weight gain have been determined. Data used in the study were collected from 68 cattle fattening farms by surveys. The sample size was determined by Simple Random Sampling Method. As a result, average 27.91, 32.50 and 18.00 upside the head cross-bred breeding animals and their culture was determined breed. $285.65 \mathrm{~kg}$ of live weight gain obtained from beef/head race and culture, was the highest in animals, feed the
\end{abstract}


animals was determined that the best benefit of race culture race again. The highest share in the costs of production was animal material and feed costs. The cost of one head of fattening animals was found for the indigenous races as TL 1779.72, for culture breeds as TL 1877.06 and for hybrid races as TL 2384.59. As a result of regression analysis, farms would obtain higher total body weight when the farms keep higher number of animals.

Keywords: Fattening duration; Live weight gain; Regression analysis; Breeding farms; Turhal district

(C) Ankara Üniversitesi Ziraat Fakültesi

\section{Giriş}

Tarımsal faaliyet, bitkisel ve hayvansal üretim ile bunların değerlendirilmesini kapsayan bir bütündür. Türkiye'de yaklaşı 3 milyon tarım işletmesi bulunmakta ve bu işletmelerin \% 2.36'sında yalnızca hayvancılık yapılmakta, \% 67.43'ünde ise bitkisel ve hayvansal üretim birlikte gerçekleştirilmektedir (TÜİK 2013a).

Hayvancılık; Türkiye'nin hem ulusal beslenme ve hem de ulusal kalkınmasında, dış satımın artırılmasında, sanayiye hammadde sağlanmasında, bölgesel ve sektörler arası dengeli kalkınma ve kalkınmanın istikrar içinde başarılmasında, kırsal alanda gizli işsizliğin önlenmesinde, sanayi ve hizmetler sektörlerinde yeni istihdam olanaklarının yaratılmasında ve kalkınma finansmanının özkaynaklara dayandırılmasında önemli bir potansiyele sahiptir (Şahin \& Yılmaz 2008). Diğer bir ifadeyle, hayvansal üretim faaliyetleri; iş verimliliğinin artırılması, işgücünün dengeli kullanımı, toprak verimliliğinin muhafazası ve artırılması açısından önem kazanmaktadır. Hayvancılık, ilgili sanayi sektörlerine hammadde sağlaması açısından da önemli bir yere sahiptir. Türkiye'nin doğal yapısı ve ekolojik şartlarına bakılarak hayvancılığa elverişli kabul edilmesine rağmen, uzun dönemler boyunca hayvansal üretimin yeterli düzeye ulaştırılamadığı hatta gerileme olduğu gözlenmiştir. Bunun sonucunda hayvan sayısının azalmasına bağlı olarak, hayvansal ürün fiyatları artmış ve bundan dolayı insanlar daha az hayvansal ürün tüketmeye başlamışlardır (Vural \& Fidan 2007). Tarım sektöründe gelişme göstermiş olan ülkelerin çoğunda hayvancılığın tarımsal üretim içerisindeki payı \% 50'nin üzerindedir (Aydemir \& Pıçak 2007).

Hayvancılık faaliyetinin ana çıktıları et ve süttür. Besicilik, bitkisel üretim ve üretim artıklarının daha ekonomik olarak değerlendirilmesinde, bölgeler arası dengeli kalkınmanın gerçekleştirilmesinde, iç ve dış pazarların besili karkas ağırlığına sahip ve kaliteli sığır eti taleplerinin karşılanmasında önemli iş alanlarından birisidir (Kabukçu 1986). Türkiye'de sığır besiciliği işletmeleri genel olarak yüksek maliyet ve düşük verimlilik ile çalışan, Avrupa ölçeğinin çok gerisinde küçük işletmeler olup, bütün yörelerde çalışma şekli hemen hemen birbirlerine benzemektedir (Yücelyiğit et al 1993).

Türkiye'de kırmızı etin kaynağını sığır, koyun, keçi ve manda oluşturmaktadır. 2011 yılı rakamlarına göre, dünyadaki sığır varlığı yaklaşık 1.4 milyar baş’tır. Türkiye'de ise 2012 yılı verilerine göre sığır sayısı 13.9 milyon baş’tır (TÜİK 2013b). Türkiye'de sığır varlığının \% 40.82'si kültür, $\%$ 41.51'i melez ve \% 17.67'si ise yerli rrklardan oluşmaktadır. Kesilen büyükbaş hayvan sayısı ise 2791034 baş olup, bu kesimlerden 799344 ton et elde edilmiştir. Sığır eti toplamı, hayvan kesimi sonucu elde edilen toplam et miktarının \% 87.28'ini oluşturmaktadır (TÜİK 2013a).Türkiye hayvancılığına genel olarak bakıldığında, sı ğırda sağlanan verim artışında, toplam sığır varlığındaki kültür ırk1 ve melez genotiplerin oranındaki artışın önemli bir payı olduğu belirtilmektedir (Koyuncu et al 2005).

Türkiye'de son yıllarda entansif besi işletmelerinin özellikle büyük tüketim merkezleri çevresinde yoğunlaştığı görülmektedir. Türkiye'de 
sığır besiciliği 1960'lı yıllardan sonra şeker fabrikası olan yerlerde gelişmeye ve yoğunlaşmaya başlamıștır. Ancak yaklaşık 30 adet șeker fabrikasının ülkeyi coğrafi bakımdan bir ağ gibi örmüş bulunması, hemen her yerde entansif veya ekstansif besiciliğe olanak sağlamıştır. Sı ̆̆ır besiciliği işletmelerinin büyük bir çoğunluğunun şeker fabrikaları etrafında yaygınlaşmasının bir diğer nedeni de, hayvan borsa ve pazarları ile irtibatlarını sağlayan yol durumunun buralarda elverişli olmasıdır (Sayılı 2001).

Şekerpancarı posası elde edemeyen veya elde etmesi ekonomik olmayan yörelerde, ucuza temin edilen diğer kaba yemler rasyona dâhil edilmektedir. Dolayısıyla Türkiye'de sığır besiciliği işletmelerinin dağ 1 lımı ve kuruluş yerini tayin eden en önemli iki faktör; beside fazla miktarda kullanılan yemin ucuza temin edilmesi ve besiye alınan sığırların işletmelere ve besili sığırların pazarlara ucuz ve az fireyle ulaştırılmasıdır (Oktay 1986).

Sığır besiciliği faaliyetleri gerekli yem kaynaklarının bol ve ucuz olduğu yörelerde yoğunlaşmaktadır. Tokat ilinde özellikle Turhal ilçesinde 19 Ekim 1934 yılında kurulan ve ülkenin kuruluş itibariyle dördüncü şeker fabrikasının olmasına bağlı olarak sığır besiciliği önemli bir faaliyet şeklinde yapılmaktadır. Bölgede sığır besiciliğinin bu kadar gelişmesinde ilçe merkezinde bulunan "Turhal Şeker Fabrikası"nın etkisi büyüktür. Özellikle fabrika tarafından çiftçilere verilen şekerpancarı küspesi besicilikte kullanılmaktadır. Bölgede besiciliğin gelişmesi, bölgeye yakın illerden göç gelmesine yol açmıştır (Gözener \& Sayılı 2011).

Araştırma bölgesi olarak seçilen Tokat ili Turhal ilçesi, bölgede sı̆̆ır besiciliğinin yoğun olarak yapıldığı bir yerdir. 2012 yılı itibariyle Türkiye'deki sığır varlığının \% 0.23 'ü araştırma bölgesinde yer almaktadır (TÜİK 2013b).

$\mathrm{Bu}$ araştırmanın amacı; ilçede şehir merkezinde bulunan sığır besicilik faaliyetinin üretim maliyetini hesaplamak ve canlı ağırlık artışına etki eden faktörleri ortaya koymaktır. Bu kapsamda; sığır besiciliği işletmelerinde, hayvan ırkları itibari ile üretim maliyetleri, canlı ağırlık ve canlı ağırlık artış maliyeti, yem masrafi ve yemden yararlanma durumları hesaplanmıştır. Ayrıca canlı ağırlık artışına etki eden faktörler regresyon analizi ile tahmin edilmeye çalışılmıştır. Elde edilen sonuçlar yorumlanmış ve besiciliğe yönelik öneriler getirilmiştir.

\section{Materyal ve Yöntem}

Çalışmanın ana materyalini, araştırma bölgesinde sığır besi işletmelerinden anket yoluyla elde edilen birincil nitelikteki veriler oluşturmuştur. Elde edilen veriler 2011-2012 üretim dönemine aittir.

Ana populasyonun tespitinde; Turhal İlçesi Gıda, Tarım ve Hayvancılık Müdürlüğü TÜRKVET kayıtlarından faydalanılmıştır. $\mathrm{Bu}$ populasyondan hayvan sayıları dikkate alınarak aşağıda formülü verilen Basit Tesadüfî Örnekleme Yöntemi kullanılarak örnek hacmi belirlenmiştir (Çiçek \& Erkan 1996):

$n=\frac{N \times S^{2} \times t^{2}}{(N-1) \times d^{2}+S^{2} \times t^{2}}$

Formülde; n, örnek sayısı; N, hayvan sayısı (3403); $\mathrm{S}$, standart sapma (12.62); D, kabul edilebilir hata (0.10); t, güven sinırı (1.65)'dır.

Yapılan hesaplama sonucunda anket yapılacak işletme sayısı (örnek hacmi) 68 olarak hesaplanmıştır.

Anketlerle elde edilen veriler doğrultusunda, besicilik faaliyeti sonucunda besi hayvanlarının canlı ağırlık artış maliyetleri ve yemden yararlanma durumları hesaplanmıştır. Ayrıca canlı ağırlık artışına etki edebileceği düşünülen faktörlere ilişkin regresyon analizi yapılmıştır.

Farklı ırklar itibariyle besiye alınan hayvanların besi başı ve besi sonu canlı ağırlıkları ile besi süreleri üretici beyanları ile tespit edilmiştir. Bu verilerden hareketle, besi hayvanlarının günlük canlı ağırlık artışları araştırıcılar tarafından hesaplanmıştır.

Canlı ağırlık artışı, canlı ağırlık artış maliyeti, yem dönüşüm oranları (yedirilen yemler ve karşı1lığında elde edilen canlı ağırlık artışı) ve yemden yararlanma durumlarının hesabında 
kullanılan formüller aşağıda verilmiştir (Kıral 1993; Kiral et al 1999; Sayılı 2001):

$\begin{array}{ll}1 \mathrm{~kg} \text { canlı ağırlık }= & \text { (Besi hayvanı alım masrafları } \\ \text { maliyeti } & \text { dâhil toplam masraflar }- \\ & \text { Gübre değeri) / Besi sonu } \\ & \text { toplam canlı ağırlık }\end{array}$

$1 \mathrm{~kg}$ canlı ağırlık $=($ Besi hayvanı alım masrafları artış maliyeti hariç toplam masraflar Gübre değeri) / Besi sonu toplam canlı ağırlık artışı

$1 \mathrm{~kg}$ canlı = Yedirilen yem miktarı $/$ Canlı ağırlık artışı için ağırlık artışı

tüketilen yem

miktarı $(\mathrm{kg})$

$1 \mathrm{~kg}$ yemden = Canlı ağırlık artışı/Yedirilen sağlanan canlı yem miktarı

ağırlık artışı $(\mathrm{kg})$

Yemden = Canlı ağırlık artışının parasal yararlanma değeri / Yapılan yem masrafı durumu (yem dönüşüm oranı)

$(\%)$

Bu çalışmada, tarımsal üretimin özellikleri de göz önüne alınarak, ekonometrik model için en uygun fonksiyon tipinin Cobb-Douglas tipi olduğu kabul edilmiştir ve kullanılmıştır. Daha önce besiciliğin fonksiyonel analizinde de genellikle bu tip fonksiyon kullanılmıştır (Karagölge 1973; Zoral 1975; Karkacier 1991; Erkuş et al 1996; Sayılı 2001).

Cobb-Douglas tipi fonksiyon üssel kalıpta olup, logaritmik dönüşümle doğrusal forma dönüştürülebilir (Karkacıer 2001):

$\mathrm{Y}=\mathrm{a} \times \mathrm{X}_{\mathrm{i}}^{\mathrm{bi}}$

ya da

$\log \mathrm{Y}=\log \mathrm{a}+\mathrm{b}_{\mathrm{i}} \times \log \mathrm{x}_{\mathrm{i}}$

Yapılan regresyon analizi ile denkleme ait determinasyon katsayısı ve kısmi regresyon katsayıları hesaplanmış, otokorelasyon olup olmadığı test edilmiştir. Üretim fonksiyonu ekonomik açıdan değerlendirilirken, ortalama verim, marjinal verim, üretim faktörlerinin etkinlik katsayıları hesaplanmış ve yorumlanmıştır.

\section{Bulgular ve Tartışma}

İncelenen işletmelerdeki hayvanların ırklara göre dağılımı, besi başı, besi sonu ağırlıkları, canlı ağırlık artışları, besi süreleri gibi besicilik faaliyetine ilişkin bazı bilgiler Çizelge 1'de verilmiştir. İşletmelerde en fazla melez, en az ise kültür rrkı hayvan ile besicilik yapılmaktadır. Kültür ırkı hayvanların besi başı ve besi sonu ağırlıkları ile besi süresinin diğer ırklara göre daha yüksek olduğu, dolayısıyla hayvanların canlı ağırlık artışının da daha fazla olduğu görülmektedir. Besi sığırcılığı faaliyetinde karlılığı etkileyen önemli faktörler arasında yer alan günlük canlı ağırlık artışına bakıldığında ise, en yüksek değerin yine kültür ırkı hayvanlara ait olduğu belirlenmiştir. Daha önce yapılmış çalışmalarda hayvan başına günlük canlı ağırlık artışları; Çorum ilinde yerli urkta 740.88 gr, melez irkta 850.30 gr ve kültür ırkında 1050 gr (Fidan 1992), Tokat ilinde yerli 1rkta 454 gr, melez ırkta 623 gr ve kültür ırkında 749 gr (Kılıç 1994), Amasya-Suluova ilçesinde yerli ırkta 757.14 gr, melez ırkta 865.89 gr ve kültür ırkında 1055.62 gr (Sayılı 2001), Amasya-Suluova ilçesinde yapılan diğer bir araştırmada da yerli ırkta 908.45 gr, melez rrkta 994.04 gr ve kültür irkında 1094.77 gr (Hazneci 2007) ve TR83 bölgesinde ise yerli rrkta 707.25 gr, melez ırkta 849.73 gr ve kültür ırkında 1338.24 gr (Gözener 2013) olarak hesaplanmıştır.

İncelenen işletmelerde besi sığırcılığı üretim masrafları Çizelge 2'de verilmiştir. Yerli ırk hayvanlar için yapılan üretim masrafi 1790.42 TL baş $^{-1}$ iken, bu değer melez 1rkı hayvanlarda 1892.06 TL baş ${ }^{-1}$ ve kültür ırkı hayvanlarda ise 2393.84 TL baş $^{-1}$ olarak belirlenmiştir. Üretim masrafları incelendiğinde her üç hayvan rrkı için de besi başı materyal masrafının masrafların neredeyse yarısını oluşturduğu, bunu izleyen en büyük masraf kaleminin yem masrafları olduğu görülmektedir.

1 baş hayvanın besi sonu maliyetinin en yüksek kültür ırkı hayvanlarda (2384.59 TL) olduğu, bunu melez irk (1877.06 TL) ve yerli irk (1779.72 TL) hayvanların izlediği saptanmıştır (Çizelge 3). 
Çizelge 1- İncelenen işletmelerde besi üretim dalında besi başı ve besi sonu canlı ağırlıkları ve canlı ağırlık artışları ile karkas randımanı

Table 1- The beginning and the end of fattening beef production branch of the enterprises surveyed live with live weight gain and carcass weights

\begin{tabular}{|c|c|c|c|}
\hline & \multicolumn{3}{|c|}{ Hayvan trkl } \\
\hline & Yerli & Melez & Kültür \\
\hline Besiye alınan hayvan sayısı (baş işletme ${ }^{-1}$ ) & 27.91 & 32.50 & 18.00 \\
\hline Besi baş1 canlı ağırlık (kg baş $\left.{ }^{-1}\right)$ & 94.38 & 94.42 & 150.00 \\
\hline Besi sonu canlı ağırlık $\left(\mathrm{kg}\right.$ baş$\left.^{-1}\right)$ & 216.24 & 267.28 & 435.65 \\
\hline Canlı ağırlık artışı $\left(\mathrm{kg}\right.$ baş $\left.{ }^{-1}\right)$ & 121.86 & 172.86 & 285.65 \\
\hline Besi süresi (gün) & 130.39 & 165.00 & 195.00 \\
\hline Günlük canlı ağırlık artışı $\left(\mathrm{g}\right.$ baş $\left.{ }^{-1}\right)$ & 1324.33 & 1096.73 & 2000.50 \\
\hline Sağlanan karkas miktarı $\left(\mathrm{kg}\right.$ baş$\left.^{-1}\right)$ & 95.75 & 133.85 & 232.85 \\
\hline Sicak karkas randımanı (\%) & 44.28 & 50.08 & 53.45 \\
\hline
\end{tabular}

Çizelge 2- İncelenen işletmelerde sığır besiciliği üretim dalında üretim masrafları (TL baş ${ }^{-1}$ ) ve oransal dağılımı (\%)

Table 2- Branch of production costs of cattle production enterprises surveyed (TL head ${ }^{-1}$ ) and proportional distribution (\%)

\begin{tabular}{|c|c|c|c|c|c|c|}
\hline & \multicolumn{6}{|c|}{ Hayvan ırkı } \\
\hline & \multicolumn{2}{|c|}{ Yerli } & \multicolumn{2}{|c|}{ Melez } & \multicolumn{2}{|c|}{ Kültür } \\
\hline & Değer & $\%$ & Değer & $\%$ & Değer & $\%$ \\
\hline Besi başı hayvan materyali & 857.43 & 47.89 & 830.77 & 43.91 & 1011.11 & 42.24 \\
\hline İşçilik & 16.72 & 0.93 & 7.69 & 0.41 & 9.72 & 0.41 \\
\hline Yem & 516.33 & 28.84 & 713.64 & 37.72 & 686.61 & 28.68 \\
\hline Yem taşıma & 4.64 & 0.26 & 12.12 & 0.64 & 8.33 & 0.35 \\
\hline $\mathrm{Su}$ & 1.25 & 0.07 & 1.31 & 0.07 & 1.70 & 0.07 \\
\hline Veteriner-ilaç & 55.56 & 3.10 & 32.31 & 1.71 & 62.22 & 2.60 \\
\hline Aşım & 6.78 & 0.38 & 10.00 & 0.53 & 5.32 & 0.22 \\
\hline Hayvan nakliye & 6.27 & 0.35 & 0.44 & 0.02 & 1.39 & 0.06 \\
\hline Borsa-komisyon & 0.00 & 0.00 & 0.00 & 0.00 & 0.00 & 0.00 \\
\hline Stopaj & 1.58 & 0.09 & 0.00 & 0.00 & 0.00 & 0.00 \\
\hline Otel-konaklama & 2.12 & 0.12 & 0.00 & 0.00 & 0.00 & 0.00 \\
\hline Hayvan yükleme-boşaltma işçilik & 0.92 & 0.05 & 0.00 & 0.00 & 4.17 & 0.17 \\
\hline Belediye harç-resim & 1.65 & 0.09 & 7.69 & 0.41 & 0.00 & 0.00 \\
\hline Aydinlatma & 7.55 & 0.42 & 4.04 & 0.21 & 13.02 & 0.54 \\
\hline Dezenfeksiyon & 4.56 & 0.25 & 1.54 & 0.08 & 4.98 & 0.21 \\
\hline Zincir-yular & 2.13 & 0.12 & 2.21 & 0.12 & 1.30 & 0.05 \\
\hline Bina değişken masraflar & 15.41 & 0.86 & 11.78 & 0.62 & 33.29 & 1.39 \\
\hline Alet-makine değişken masraflar & 2.83 & 0.16 & 1.71 & 0.09 & 10.00 & 0.42 \\
\hline Döner sermaye faizi $(0.05)$ & 75.19 & 4.20 & 81.86 & 4.33 & 92.66 & 3.87 \\
\hline Değişken masraflar toplamı (A) & 1578.91 & 88.19 & 1719.10 & 90.86 & 1945.83 & 81.28 \\
\hline Genel idare giderleri $(\mathrm{A} * 0.03)$ & 47.37 & 2.65 & 51.57 & 2.73 & 58.38 & 2.44 \\
\hline Bina sermayesi amortismanı & 61.64 & 3.44 & 47.12 & 2.49 & 133.17 & 5.56 \\
\hline Bina sermayesi faizi & 30.82 & 1.72 & 23.56 & 1.25 & 66.59 & 2.78 \\
\hline Bina y1llık tamir-bakımı & 46.23 & 2.58 & 35.34 & 1.87 & 99.88 & 4.17 \\
\hline Alet-makine sermayesi amortismanı & 11.31 & 0.63 & 6.83 & 0.36 & 40.00 & 1.67 \\
\hline Alet-makine sermayesi faizi & 5.65 & 0.32 & 3.42 & 0.18 & 20.00 & 0.84 \\
\hline Alet-makine yıllık tamir-bakımı & 8.48 & 0.47 & 5.12 & 0.27 & 30.00 & 1.25 \\
\hline Sabit masraflar toplamı (B) & 211.51 & 11.81 & 172.96 & 9.14 & 448.01 & 18.72 \\
\hline Üretim masrafları toplamı $(\mathrm{A}+\mathrm{B})$ & 1790.42 & 100.00 & 1892.06 & 100.00 & 2393.84 & 100.00 \\
\hline
\end{tabular}


Çizelge 3- İncelenen işletmelerde 1 baş besi hayvanının besi sonu maliyeti

Table 3- The cost of 1 head of fattening beef animals from the study

\begin{tabular}{lrrr}
\hline & \multicolumn{3}{c}{ Hayvan ırkl } \\
\cline { 2 - 4 } & \multicolumn{1}{c}{ Yerli } & \multicolumn{1}{c}{ Melez } & \multicolumn{1}{c}{ Kültür } \\
\hline Üretim masrafi (TL & 1790.42 & 1892.06 & 2393.84 \\
baş $\left.^{-1}\right)(1)$ & & & \\
${\text { Gübre geliri }\left(\mathrm{TL} \mathrm{bas}^{-1}\right)(2)}^{\text {1 baş hayvanın maliyeti }}$ & 10.70 & 15.00 & 9.25 \\
\hline \begin{tabular}{l} 
(TL) $(1-2)$ \\
\hline
\end{tabular}
\end{tabular}

İşletmelerde besiye alınan hayvanlardaki $1 \mathrm{~kg}$ canlı ağırlık maliyeti; yerli ırkta $8.23 \mathrm{TL}$, melez ırkta 7.02 TL ve kültür ırkında ise 5.47 TL'dir (Çizelge 4).

Çizelge 4- İncelenen işletmelerde sığır besiciliğinde $1 \mathbf{~ k g}$ canlı ağırlık maliyeti

Table 4- The cost of $1 \mathrm{~kg}$ of live weight of cattle fattening enterprises surveyed

\begin{tabular}{lrrr}
\hline & \multicolumn{3}{c}{ Hayvan ırkı } \\
\cline { 2 - 4 } & \multicolumn{1}{c}{ Yerli } & \multicolumn{1}{c}{ Melez } & \multicolumn{1}{c}{ Kültü̈r } \\
\hline Üretim masrafı TL baş ${ }^{-1}(1)$ & 1790.42 & 1892.06 & 2393.84 \\
Gübre geliri TL baş ${ }^{-1}(2)$ & 10.70 & 15.00 & 9.25 \\
Besi sonu canlı ağırlık & 216.24 & 267.28 & 435.65 \\
$\mathrm{~kg} \mathrm{bas}^{-1}(3)$ & & & \\
\hline 1 kg canlı ağırlık maliyeti & 8.23 & 7.02 & 5.47 \\
(TL) $[(1-2) / 3]$ & & & \\
\hline
\end{tabular}

Araştırmada ayrıca besi hayvanlarında $1 \mathrm{~kg}$ canlı ağırlık artış maliyeti de hesaplanmıştır (Çizelge 5). 1 kg canlı ağırlık artış maliyeti; 4.26 TL ile en yüksek düzeyde yerli ırk, 3.15 TL ile de en düşük düzeyde kültür ırkı hayvanlara aittir.

\section{Çizelge 5- İncelenen işletmelerde sığır besiciliğinde $1 \mathbf{~ k g}$ canlı ağırlık artış maliyeti}

Table 5- The cost of $1 \mathrm{~kg}$ live weight gain of cattle fattening enterprises surveyed

\begin{tabular}{|c|c|c|c|}
\hline & \multicolumn{3}{|c|}{ Hayvan ırkı } \\
\hline & Yerli & Melez & Kültür \\
\hline $\begin{array}{l}\text { Üretim masrafi (TL } \\
\left.\text { ișletme }{ }^{-1}\right)(1)^{*}\end{array}$ & 932.99 & 1061.29 & 1382.73 \\
\hline Gübre geliri (TL işletme ${ }^{-1}$ ) (2) & 10.70 & 15.00 & 9.25 \\
\hline $\begin{array}{l}\text { Besi sonu canlı ağırlık artışı } \\
\left(\mathrm{kg}^{2} \text { işletme }{ }^{-1}\right)(3)\end{array}$ & 121.86 & 172.86 & 285.65 \\
\hline $\begin{array}{l}1 \text { kg canlı ağırlık artış } \\
\text { maliyeti (TL) }[(1-2) / 3]\end{array}$ & 4.26 & 3.92 & 3.15 \\
\hline
\end{tabular}

İşletmelerde besi hayvanı başına yem masrafları Çizelge 6'da verilmiştir. Tüm hayvan ırklarında en yüksek yem harcaması karma yemlere ait olup, bu oran yerli ırk hayvanlarda daha yüksektir. Hayvan başına yapılan yem masrafi; yerli ırkta 516.33 TL, melez irkta 713.64 TL ve kültür irkında ise 686.61 TL olarak belirlenmiştir.

Besicilikte karlılığ yemden yararlanma durumudur. Yemden yararlanma durumu fiziksel ve parasal olarak iki şekilde hesaplanabilir. $\mathrm{Bu}$ araştırmada da besi hayvanlarının yemden yararlanma durumları fiziksel ve parasal olarak ayrı ayrı ele alınmıştır.

Öncelikle yemden yararlanma durumları fiziksel olarak hesaplanmıştır. Yapılan araştırma sonucunda, yerli ırk hayvanların $1 \mathrm{~kg}$ canlı ağırlık artışı için $37.37 \mathrm{~kg}$ yem tükettikleri, tükettikleri 1 $\mathrm{kg}$ yem karşılığında ise $0.03 \mathrm{~kg}$ canlı ağırlık artışı elde ettikleri belirlenmiştir (Çizelge 7). Bu değerler, sırasiyla; melez 1rk1 hayvanlarda $17.83 \mathrm{~kg}$ ve 0.07 $\mathrm{kg}$, kültür 1 rk1 hayvanlarda ise $15.61 \mathrm{~kg}$ ve 0.06 kg'dır. $1 \mathrm{~kg}$ canlı ağırlık için besi hayvanı başına tüketilen yem miktarı; Kılıç (1994) tarafından kültür 1rkında $5.95 \mathrm{~kg}$, melez 1rkında $7.55 \mathrm{~kg}$ ve yerli 1 rkta $8.83 \mathrm{~kg}$, Sayılı (2001)'nın araştırmasında yerli ırkta $9.11 \mathrm{~kg}$, melez irkta $8.61 \mathrm{~kg}$ ve kültür ırkında 7.67 kg, Hazneci (2007)'nin araştırmasında yerli ırkta $12.27 \mathrm{~kg}$, melez irkta $11.20 \mathrm{~kg}$ ve kültür irkında $11.91 \mathrm{~kg}$, Gözener (2013)'in araştırmasında ise yerli 1rkta $14.77 \mathrm{~kg}$, melez 1rkta $7.93 \mathrm{~kg}$ ve kültür ırkında $4.42 \mathrm{~kg}$ olarak belirlenmiştir.

İncelenen işletmelerde parasal olarak yemden faydalanma durumları; yerli 1 rk hayvanlarda $\% 346.23$, melez rrk hayvanlarda \% 357.52 ve kültür ırkı hayvanlarda ise \% 614.06 olarak hesaplanmıştır (Çizelge 8). Bu oranın anlamı; 100 TL'lik yem masrafına karşılık yerli ırkta 346.23 TL, melez ırkta 357.52 TL ve kültür ırkında ise 614.06 TL karşıllğı canlı ağırlık artışı sağlandığıdır. Parasal yemden yararlanma durumu, Amasya-Suluova ilçesindeki besi işletmelerinde yerli irklarda \% 229.56, melez rrklarda \% 236.15 ve kültür ırklarında ise \% 284.03 olarak hesaplanmıştır (Sayılı 2001).

İncelenen işletmelerdeki besi hayvanlarındaki canlı ağırlık artışı ile bunu etkileyebilecek faktörler arasında ilişkiyi ortaya koymak amacıyla çoklu regresyon ve korelasyon analizleri yapılmıştır. 
Çizelge 6- İncelenen işletmelerde sığır besiciliğinde besi dönemi boyunca hayvan başına yapılan yem masrafları (TL baş ${ }^{-1}$ ) ve oransal dağılımı (\%)

Table 6- Fattening beef cattle enterprises per capita over the period examined in animal feed costs (TL head ${ }^{-1}$ ) and proportional distribution (\%)

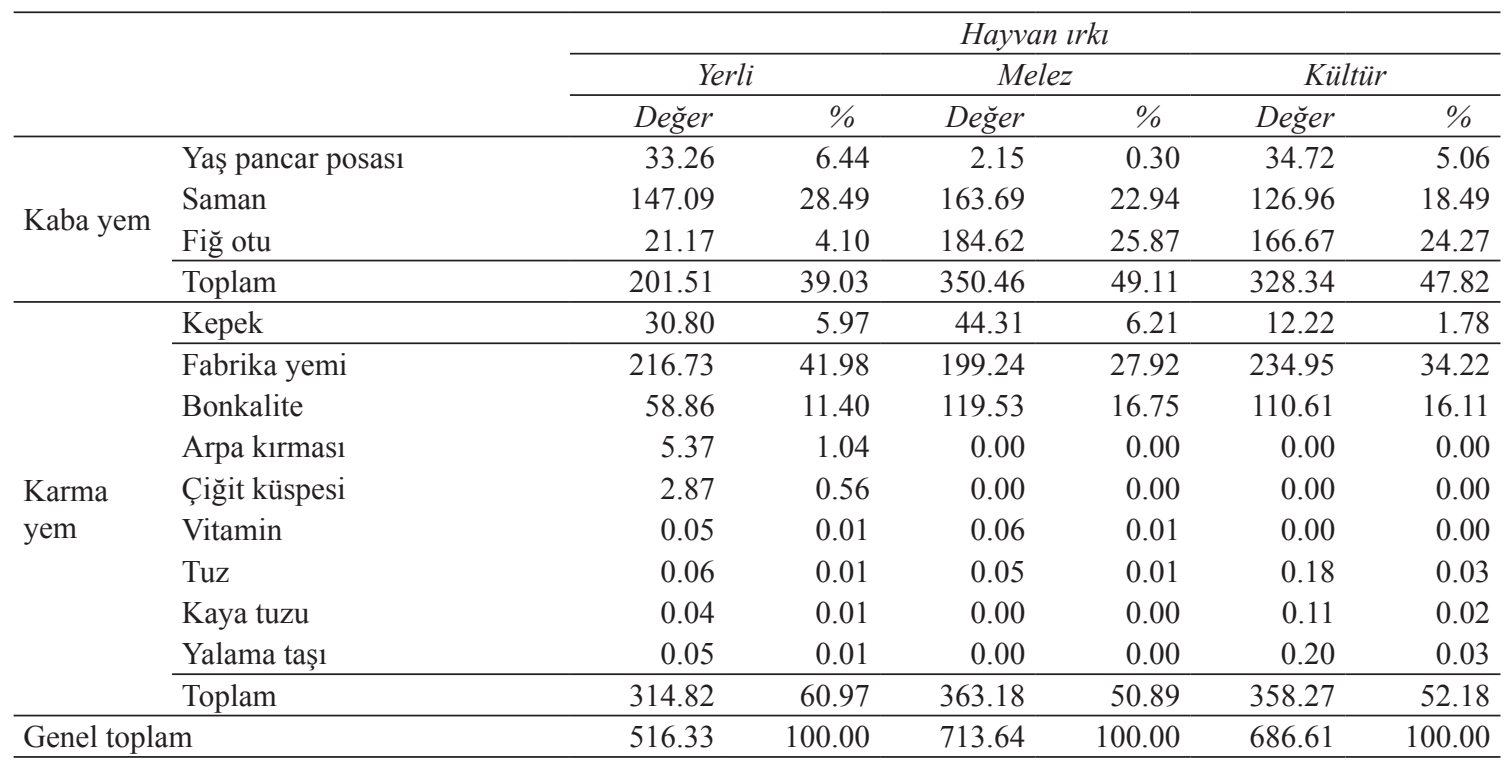

Çizelge 7- İncelenen işletmelerde sığır besiciliği üretim dalında yemden yararlanma durumu (kuru madde cinsinden)

Table 7-Branch of the enterprises surveyed cattle feed efficiency of production status (in terms of dry matter)

\begin{tabular}{lrrr}
\hline & \multicolumn{3}{c}{ Hayvan ırkı } \\
\cline { 2 - 4 } & \multicolumn{1}{c}{ Yerli } & Melez & Kültü̈r \\
\hline Canlı ağırlık artışı $\left(\mathrm{kg} \mathrm{baş}{ }^{-1}\right)(1)$ & 121.86 & 172.86 & 285.65 \\
\hline Tüketilen yem miktarı $\left(\mathrm{kg} \mathrm{baş}^{-1}\right)(2)$ & 4554.47 & 3082.04 & 4459.75 \\
\hline 1 kg canlı ağırlık artı̧̧ için tüketilen yem miktarı $\left(\mathrm{kg} \mathrm{baş}^{-1}\right)(2 / 1)$ & 37.37 & 17.83 & 15.61 \\
\hline 1 kg yemden bağlanan canlı ağırlık artış1 $\left(\mathrm{kg} \mathrm{baş}^{-1}\right)(1 / 2)$ & 0.03 & 0.07 & 0.06 \\
\hline
\end{tabular}

Çizelge 8- İncelenen işletmelerde sığır besiciliğinde yemden yararlanma durumu (\%)

Table 8-Status of the enterprises surveyed cattle fattening feed efficiency (\%)

\begin{tabular}{lccc}
\hline & \multicolumn{3}{c}{ Hayvan ırkı } \\
\cline { 2 - 4 } & Yerli & Melez & Kültür \\
\hline Canlı ağırlık artışı (TL & 1787.69 & 2551.41 & 4216.19 \\
baş $^{-1}$ ) (1) & & & \\
Yem masrafi (TL baş & & & \\
Yem (2) & 516.33 & 713.64 & 686.61 \\
Yemden yararlanma & 346.23 & 357.52 & 614.06 \\
durumu (1/2*100) & & & \\
\hline
\end{tabular}

Üretim fonksiyonu ve fonksiyonda yer alan değişkenler Çizelge 9'da verilmiştir. Fonksiyona ilişkin elde edilen denklem aşağıdaki gibidir:

$\mathrm{Y}=1.1530+\mathrm{X}_{1}^{0.4059} \mathrm{X}_{2}^{-0.01589} \mathrm{X}_{3}^{0.003460} \mathrm{X}_{4}^{0.001724}$ $\mathrm{X}_{5}^{0.5209} \mathrm{X}_{6}^{0.2448} \mathrm{X}_{7}^{-0.01293}$

$\log \mathrm{Y}=1.1530+0.4059 \mathrm{X}_{1}-0.01589 \mathrm{X}_{2}+0.003460$

$\mathrm{X}_{3}+0.001724 \mathrm{X}_{4}+0.5209 \mathrm{X}_{5}+0.2448 \mathrm{X}_{6}-0.01293$

$\mathrm{X}_{7}$ 


\section{Çizelge 9- Regresyon analizinde kullanılan değişkenler ve açıklamaları}

Table 9- The variables used in the regression analysis and descriptions of their

\begin{tabular}{|c|c|c|}
\hline Bağımlı değişken & $\mathrm{Y}$ & Üretim miktarı (işletme başına elde edilen toplam canlı ağırlık artışı - kg) \\
\hline \multirow{7}{*}{ Bağımsız değişkenler } & $\mathrm{X}_{1}$ & Besiye alınan hayvan sayıs1 (adet) \\
\hline & $\mathrm{X}_{2}$ & Besi süresi (besi sığırlarının beside toplam kalış süreleri - gün) \\
\hline & $\mathrm{X}_{3}$ & İşgücü (sığır besiciliğinde besi dönemi boyunca kullanılan toplam işgücü - EİG) \\
\hline & $\mathrm{X}_{4}$ & Sağlık giderleri (besi sığırlarına yılda yapılan veteriner, ilaç vb. giderler - TL) \\
\hline & $X_{5}^{4}$ & Besi başı canlı ağırlık (besiye alınan hayvanların besi başı canlı ağırlıkları - kg) \\
\hline & $\mathrm{X}_{6}$ & $\begin{array}{l}\text { Karma yem miktarı (besi sığırlarının besi süresince kuru madde cinsinden tükettikleri } \\
\text { toplam kesif yem miktarı - kg) }\end{array}$ \\
\hline & $\mathrm{X}_{7}$ & $\begin{array}{l}\text { Kaba yem miktarı (besi sığırlarının besi süresince kuru madde cinsinden tükettikleri } \\
\text { toplam kaba yem miktarı - kg) }\end{array}$ \\
\hline
\end{tabular}

Çizelge 10- Üretim fonksiyonunda yer alan üretim faktörlerinin üretim elastikiyetleri ve önem derecesi Table 10- Elasticities of production factors in the production function and importance of production

\begin{tabular}{|c|c|c|c|c|}
\hline $\begin{array}{c}\text { Bağımsız } \\
\text { değişkenler }\end{array}$ & $\begin{array}{c}\text { Regresyon } \\
\text { katsayılarl }\left(b_{i}\right)\end{array}$ & $\begin{array}{c}\text { Regresyon katsayılarının } \\
\text { standart sapması }\left(S b_{i}\right)\end{array}$ & $\begin{array}{l}\text { t-hesap } \\
\text { değeri }\end{array}$ & $\begin{array}{c}\text { Önem derecesi } \\
(P)\end{array}$ \\
\hline Sabit terim (a) & 1.1530 & 0.3079 & 3.74 & 0.000 \\
\hline $\mathrm{X}_{1}$ & 0.4059 & 0.1613 & 2.52 & 0.014 \\
\hline$X_{2}$ & -0.01589 & 0.04584 & -0.35 & 0.730 \\
\hline$x_{3}^{2}$ & 0.003460 & 0.005236 & 0.66 & 0.511 \\
\hline$X_{4}$ & 0.001724 & 0.004074 & 0.42 & 0.673 \\
\hline $\mathrm{X}_{5}$ & 0.5209 & 0.1483 & 3.51 & 0.001 \\
\hline$X_{6}$ & 0.2448 & 0.02662 & 0.92 & 0.361 \\
\hline $\mathrm{X}_{7}$ & -0.01293 & 0.02577 & -0.50 & 0.617 \\
\hline
\end{tabular}

Yapılan regresyon analizinde determinasyon katsayısı $\left(\mathrm{R}^{2}\right) 0.933$ olarak hesaplanmıştır (Çizelge 10). Bu sonuç fonksiyondakibağımsızdeğişkenlerdeki değişmelerin, bağımlı değişkendeki değişmelerin \% 93.3'ünü açılayacağını göstermektedir. Fonksiyonun düzeltilmiş determinasyon katsayısı ( $\mathrm{R}^{2}$-adj) 0.927 ve standart hatası da 0.09665 olarak hesaplanmıştır.

$\mathrm{F}$ istatistik testine göre model \% 1 düzeyinde anlamlı bulunmuştur ( $\mathrm{F}_{\text {hes }}$ : $152.92>\mathrm{F}_{0.01}$ : 3.17). Bağımsız değişkenlerin her birinin anlamlı olup olmadıklarına bakıldığında ise $\mathrm{X}_{1}$ değgişkeni \% 5 ve $\mathrm{X}_{5}$ değişkeni \% 1 düzeyinde önemli, $\mathrm{X}_{2}, \mathrm{X}_{3}, \mathrm{X}_{4}, \mathrm{X}_{6}$ ve $\mathrm{X}_{7}$ değişkenleri ise önemsiz bulunmuştur ve bu faktörler için yorum yapılmamıştır.
Fonksiyonda çoklu bağıntı problemi olup olmadığı korelasyona bakılarak tespit edilmeye çalışılmıştır. Korelasyon matriksi incelendiğinde $\mathrm{X}_{1}$ ile $\mathrm{X}_{5}$ arasında pozitif yönlü ve güçlü bir ilişki olduğu görülmüş̧ür (Çizelge 11).

Çizelge 11- Değişkenlere ilişkin korelasyon matriksi Table 11-Correlation matrix for the variables

\begin{tabular}{lrrrrrr}
\hline & $X_{1}$ & $X_{2}$ & $X_{3}$ & $X_{4}$ & $X_{5}$ & $X_{6}$ \\
\hline $\mathrm{X}_{2}$ & 0.322 & & & & & \\
$\mathrm{X}_{3}$ & -0.167 & 0.256 & & & & \\
$\mathrm{X}_{4}$ & -0.028 & 0.073 & 0.094 & & & \\
$\mathrm{X}_{5}$ & 0.980 & -0.276 & 0.181 & -0.022 & & \\
$\mathrm{X}_{6}$ & 0.733 & -0.305 & -0.030 & 0.122 & 0.702 & \\
$\mathrm{X}_{7}$ & 0.521 & -0.142 & 0.043 & 0.011 & 0.512 & 0.296 \\
\hline
\end{tabular}


Otokorelasyon problemi, araştırmalarda kullanılan verilere bağlı olarak değişmektedir. Genellikle otokorelasyon probleminin ortaya çıkması, zaman serilerine dayalı araştırmalarda daha yaygındır. Ancak yine de bu araştırmada otokorelasyon problemi olup olmadı̆̆ı incelenmiştir.

Denkleme ilişkin otokorelasyon problemi Durbin-Watson istatistiğine göre araştırılmıştır. Denkleme ait Durbin-Watson istatistiği $(\mathrm{d})=1.68$, $\mathrm{n}=68, \mathrm{k}=5, \% 5$ önem düzeyinde $\mathrm{dl}=1.542$ ve $\mathrm{du}=1.776^{\prime} \mathrm{d}$.r.

Hesap değeri ile kritik tablo değerleri karşılaştırıldığında; $\mathrm{du}<\mathrm{d}<\mathrm{d}$ l sonucuna göre kararsız bölge görünmektedir. $\mathrm{Bu}$ durumda otokorelasyon probleminin olup olmadığını görebilmek amacıyla Von-Neumann testine başvurulmuştur. VonNeumann istatistiğine ulaşmak için Durbin-Watson istatistik değeri (d) kullanılmıştır.

$\mathrm{d}=1.67$

$\mathrm{v}=\mathrm{d} *\left(\mathrm{n}^{\prime} \mathrm{n}^{\prime}-1^{-1}\right)$

$\mathrm{v}=1.68 *\left(6362^{-1}\right)=1.71$

$\mathrm{n}^{\prime}=\mathrm{n}-\mathrm{k}=68-5=63$

$\mathrm{n}^{\prime}-1=63-1=62$

Von-Neumann değeri(v) 1.71 olup, \% 1 düzeyinde otokorelasyon problemine rastlanmamıştır (kritik tablo değerleri; $\mathrm{v}=1.44 \mathrm{ve} \mathrm{v}^{*}=2.63$ ).

Cobb-Douglas tipi üretim fonksiyonlarının özelliği gereğince, fonksiyonda yer alan değişkenlerin katsayıları ait oldukları üretim faktörünün marjinal üretim elastikiyetini vermektedir. Marjinal elastikiyetlerin toplamı aynı zamanda ölçeğe getiriyi belirlemektedir (Zoral 1984).

Tahmin edilen denklemde üretim elastikiyetleri toplamı 1.147964'tür. Üretim esnekliği, üretim faktörlerinin miktarındaki \% 1 değişme karşısında, üretim miktarında meydana gelen \% değişme olarak tanımlanmaktadır (Yaylalı 1994). Denklemdeki bağımsız değişkenlerin tümü birden \% 1 artırılmasıyla üretim miktarı \% 1.15 artacaktır. Bu durum ölçeğe göre artan getiriyi göstermektedir.
Sayılı (2001) tarafından yapılan araştırmada, besi sığırcılığında canlı ağırlık artışına etki eden ve istatistiksel açıdan anlamlı olan faktörler; besi süresince kuru madde cinsinden besi hayvanlarının tükettikleri kaba yem miktarı $(\mathrm{kg})$, besiye alınan hayvanların besi başı canlı ağırlıkları (kg), besiye alınan yerli ırk hayvan sayısı (baş), besiye alınan kültür ırkı hayvan sayısı (baş), işletmelerdeki mevcut ahırların kullanılabilir kapasitesi $\left(\mathrm{m}^{2}\right)$, besi süresi (gün) ve besi süresi döneminde kullanılan toplam işgücü miktarı (EİG) olarak tespit edilmiştir. Regresyon analizinde kullanılan Cobb-Douglas üretim fonksiyonuna ait determinasyon katsayıs1 $\left(\mathrm{R}^{2}\right) 0.939$ olarak hesaplanmıştır. Tahmin edilen denkleme ilişkin üretim elastikiyetleri toplamı $1.4398^{\prime}$ dir.

Üretim fonksiyonunda yer alan üretim faktörlerinin marjinal üretim elastikiyetleri aşağıdaki şekilde açıklanabilir:

- $\mathrm{X}_{1}$ (Besiye alınan hayvan sayısı): Bu üretim faktörünün katsayısının işareti pozitiftir. İstatistiksel açıdan üretim miktarını açıklamakta önemli bulunmuştur. Besiye alınan hayvan sayısının \% 1 artması (diğer üretim faktörlerinin aynı düzeyde kalması şartıyla) üretim miktarını da \% 0.4059 artıracaktır.

- $\mathrm{X}_{2}$ (Besi süresi): Bu üretim faktörünün kısmi regresyon katsayısı anlamlı çıkmamıştır.

- $\mathrm{X}_{3}$ (İşgücü): $\mathrm{Bu}$ üretim faktörünün kısmi regresyon katsayısı anlamlı çıkmamıştır.

- $\mathrm{X}_{4}$ (Sağlık giderleri): $\mathrm{Bu}$ üretim faktörünün kısmi regresyon katsayısı anlamlı çıkmamıştır.

- $X_{5}$ (Besi başı canlı ağırlık): Bu üretim faktörünün katsayısının işareti pozitiftir. İstatistiksel olarak üretim miktarını açıklamada yeterli bulunmuştur. Diğer üretim faktörlerinin aynı düzeyde kalması koşuluyla, sığırların besi başı canlı ağırlıklarının $\% 1$ artırılması neticesinde, üretim miktarında $\% 0.5209$ birimlik bir artış söz konusudur.

- $\mathrm{X}_{6}$ (Karma yem miktarı): Bu üretim faktörünün kısmi regresyon katsayısı anlamlı çıkmamıştır.

- $\mathrm{X}_{7}$ (Kaba yem miktarı): $\mathrm{Bu}$ faktörün kısmi regresyon katsayısı anlamlı çıkmamıştır. 
Bir üretim faktörünün belirli bir ürün üretiminde ne derece etkin kullanıldığı etkinlik katsayısı ile belirlenmektedir.

Üretim faktörlerinin marjinal verimlerine ulaşmak amacıyla öncelikle logaritması alınmış olan ortalamaların (Çizelge 12) anti logaritması alınarak geometrik ortalamalar elde edilmiştir (Çizelge 13). Ortalama üretim miktarları belirlendikten sonra her bir üretim faktörüne ait katsayılar ile çarpılarak marjinal verimler elde edilmiştir. Marjinal verimlerin faktör fiyatları ile çarpılması ile de marjinal gelire ulaşılmıştır.

\section{Çizelge 12- Tanımlama istatistikleri}

Table 12- Descriptive statistics

\begin{tabular}{|c|c|c|c|c|}
\hline 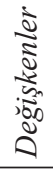 & 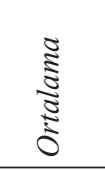 & 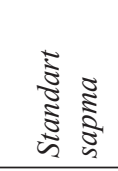 & 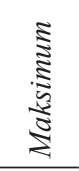 & 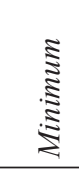 \\
\hline Y & 3.3832 & 0.36658 & 4.22 & 2.72 \\
\hline $\mathrm{X}_{1}$ & 1.2785 & 0.36387 & 2.18 & 0.70 \\
\hline$X_{2}$ & 2.0616 & 0.26251 & 2.56 & 1.48 \\
\hline$X_{3}$ & 1.7114 & 2.16450 & 3.01 & -6.00 \\
\hline$X_{4}$ & 2.0829 & 2.65870 & 4.26 & -6.00 \\
\hline$X_{5}$ & 3.2586 & 0.37138 & 4.11 & 2.60 \\
\hline$X_{6}$ & 3.0636 & 0.61884 & 4.23 & 1.64 \\
\hline$X_{7}$ & 3.2254 & 0.49430 & 4.10 & 2.24 \\
\hline
\end{tabular}

Çizelge 13- Tahmin fonksiyonuna ilişsin faktörlerin geometrik ortalama, ortalama üretim ve marjinal verimler

Table 13- Prediction of the factors related to the function of the geometric mean, the average production and marginal yields

\begin{tabular}{crrr}
\hline Değişkenler & $\begin{array}{r}\text { Geometrik } \\
\text { ortalama }\end{array}$ & $\begin{array}{r}\text { Ortalama } \\
\text { üretim }\end{array}$ & $\begin{array}{r}\text { Marjinal } \\
\text { verim }\end{array}$ \\
\hline $\mathrm{X}_{1}$ & 18.9889 & 127.2622 & 51.65574 \\
$\mathrm{X}_{2}$ & 115.239 & 20.97007 & -0.333210 \\
$\mathrm{X}_{3}$ & 51.4517 & 46.96774 & 0.162508 \\
$\mathrm{X}_{4}$ & 121.032 & 19.96637 & 0.034422 \\
$\mathrm{X}_{5}$ & 1813.84 & 1.332295 & 0.693992 \\
$\mathrm{X}_{6}$ & 1157.71 & 2.087371 & 0.510988 \\
$\mathrm{X}_{7}$ & 1680.35 & 1.438135 & -0.018600 \\
\hline$\overline{\mathrm{Y}}_{\text {ort }}=2416.57$ & & & \\
\hline
\end{tabular}

Faktörlerin mevcut kullanımlarına göre artırılıp azaltılacağına karar verebilmek için faktörlerin etkinlik katsayılarına bakmak gerekir. Etkinlik katsayısının 1 olması üretim faktörünün tam etkin kullanıldığ 1 anlamına gelmektedir. 1'den büyük olması üretim faktörünün az kullanıldığı arttırılması gerektiği, 1'den küçük olması ise fazla kullanıldığı azaltılması gerektiğini göstermektedir. Araştırmada, bağımsız değişkenlere ilişkin etkinlik katsayıları Çizelge 14'te verilmiştir.

- $\mathrm{X}_{1}$ (Besiye alınan hayvan sayısı): Faktöre ait marjinal gelir 757.79 TL ve etkinlik katsayıs1 ise 0.28 olarak hesaplanmıştır. $\mathrm{Bu}$ sonuca göre, faktör aşırı kullanılmakta ve azaltılması gerekmektedir.

- $\mathrm{X}_{2}$ (Besi süresi): $\mathrm{Bu}$ üretim faktörünün kısmi regresyon katsayısı anlamlı çıkmadığı için yorumlanmamıştır.

- $\mathrm{X}_{3}$ (Kullanılan işgücü): $\mathrm{Bu}$ üretim faktörünün kısmi regresyon katsayısı anlamlı çıkmadığı için yorumlanmamıştır.

- $\mathrm{X}_{4}$ (Sağlık giderleri): $\mathrm{Bu}$ üretim faktörünün kısmi regresyon katsayısı anlamlı çıkmadığı için yorumlanmamıştır.

- $\mathrm{X}_{5}$ (Besi başı canlı ağırlık): Faktörün marjinal verimi 0.69 ve marjinal geliri de 10.18 TL olarak tespit edilmiştir. Faktörün etkinlik katsayısı 1.28 olup, faktör az kullanılmaktadır ve artırılması gerekmektedir.

- $\mathrm{X}_{6}$ (Karma yem miktarı): Bu faktörün kısmi regresyon katsayısı anlamlı çıkmadığı için yorumlanmamıştır.

- $\mathrm{X}_{7}$ (Kaba yem miktarı): Bu faktörün kısmi regresyon katsayısı anlamlı çıkmadığı için yorumlanmamıştır.

\section{Sonuçlar}

Yapılan çalışma sonucunda, araştırma yöresindeki işletmelerde besiciliğin tüm ırklar itibariyle yoğun bir şekilde yapıldı̆̆ 1 tespit edilmiştir. Yapılan tüm tespit ve hesaplamalar neticesinde, en karlı besiciliğin kültür ırkı hayvanlar ile yapıldığında (canlı ağırlık artışı yüksek, yemden yararlanması en iyi olması 
Çizelge 14- Bağımsız değişkenlere ait marjinal gelir, faktör fiyatı ve etkinlik katsayısı

Table 14-Marginal revenue of the independent variables, factor price and activity coefficient

\begin{tabular}{|c|c|c|c|c|}
\hline $\begin{array}{c}\text { Bağımsız } \\
\text { değişkenler }\end{array}$ & $\begin{array}{l}\text { Marjinal gelir } \\
(M G)\end{array}$ & $\begin{array}{c}\text { Faktör fiyatı } \\
(M M)^{*}\end{array}$ & $\begin{array}{c}\text { Etkinlik katsaylsı (MG/ } \\
M M)\end{array}$ & Yorum \\
\hline $\mathrm{X}_{1}$ & 757.789706 & 2658.14 & 0.2850827 & Fazla kullanılıyor, azaltılmalı \\
\hline $\mathrm{X}_{2}$ & -4.8881907 & 396.30 & -0.012335 & Fazla kullanılıyor, azaltılmalı \\
\hline $\mathrm{X}_{3}$ & 2.38399236 & 30.28 & 0.0787316 & Fazla kullanılıyor, azaltılmalı \\
\hline $\mathrm{X}_{4}$ & 0.50497074 & 1507.44 & 0.000335 & Fazla kullanılıyor, azaltılmalı \\
\hline$X_{5}^{4}$ & 10.1808626 & 7.97 & 1.2773981 & Az kullanılıyor, artırılmalı \\
\hline$X_{6}$ & 7.49619396 & 4.66 & 1.6086253 & Az kullanılıyor, artırılmalı \\
\hline $\mathrm{X}_{7}^{0}$ & -0.272862 & 4.86 & -0.056144 & Fazla kullanılıyor, azaltılmalı \\
\hline
\end{tabular}

*, üretim faktörlerinin fiyatları (fırsat maliyetler); $\mathrm{X}_{1}$, besiye alınan sı̆̆ırların besi başı değerleri ortalaması; $\mathrm{X}_{2}$, işletme başına düşen döner işletme sermayesinin toplam besi süresine bölünmesi sonucu bulunan değerin cari faiz karşıllı̆ı ile çarpilmasıyla elde edilen değer; $X_{3}$, araştırma bölgesindeki erkek yetişkin bir işçinin bir günlük ücreti; $X_{4}$, işletmelerde yapılmış olan sağlık giderleri toplamı; $X_{5}$, besiye alınan sığırların değerlerinin canlı ağırlıklarına bölünmesi suretiyle elde edilen değer; $X_{6}, 1 \mathrm{~kg}$ karma yemin fiyatı; $X_{7}, 1 \mathrm{~kg}$ kaba yemin fiyatı

gibi nedenlerle) gerçekleşeceği belirlenmiştir. Diğer açıdan, besi başı materyali olarak kültür ırkı besi hayvanı bulmak hem zor ve hem de pahalıdır. İşletmeler; finansal durumları, istenilen düzeyde hayvan bulabilme ve diğer imkânlar açısından besiye alacakları hayvanlara karar vermektedir. Besi hayvanının bulunabilmesi ve işletmenin finansman durumunun uygun olması halinde günlük canlı ağırlık artışı ve yemden yararlanma oranı en yüksek olan kültür ırkı hayvanlar ile besicilik yapılmalıdır. Bu kapsamda, besiciler uygun kredi imkânlarından yararlandırılmalıdır.

Tüm rrklar itibariyle, besi üretim maliyeti içerisinde yem giderleri en yüksek paya (besi baş1 hayvan materyali hariç tutulduğunda) sahiptir. Besiye alınan rrklara göre değişmekle birlikte, yem giderlerinin \% 50-60 arasinı karma yemler oluşturmaktadır. İşletmelerin tamamının şehir merkezinde olmaları nedeniyle, tüm yemler para ile satın alınmakta olup bu da üretim maliyetini artırmaktadır. $\mathrm{Bu}$ nedenle, karlı bir besicilik faaliyetinin yapılabilmesi için besiye alınan hayvanlarda canlı ağırlık artışının daha yüksek sağlanması (bu durum hayvanın ırkı, yaşı, cinsiyeti gibi birçok faktöre bağlıdır) ile birlikte özellikle yem giderlerinin daha da düşürülmesi (işletmenin kendi yemini üretebilmesi, silaj yapabilmesi gibi) gerektiğini göstermektedir.
İlçede üreticilerin besicilik konusunda herhangi bir örgütlenmeleri bulunmamaktadır. $\mathrm{Bu}$ nedenle, besicilerin öncelikle bir örgütlenmeye gitmesi gerekmektedir. Etkin ve iyi işleyen bir örgütlenme, besicilik faaliyetinde başta girdi temini ve pazarlama olmak üzere birçok sorunlara çözüm üretebilecektir. $\mathrm{Bu}$ bağlamda, üreticilerin bilgilendirilmesi ve cesaretlendirilmesi gerekmektedir.

Yapılan regresyon analizi sonucunda, işletmelerin daha düşük canlı ağırlığa sahip daha fazla hayvan ile besicilik yaptığında, toplamda daha fazla canlı ağırlık elde edecekleri saptanmıştır. Bu şekildeki davranış neticesinde, işletmelerin gelirleri de artmış olacaktır.

\section{Kaynaklar}

Aydemir C \& Pıçak M (2007). GAP Bölgesi'nde hayvancilığın gelişimi ve Türkiye içindeki konumu. Elektronik Sosyal Bilimler Dergisi 6(22): 13-37

Çiçek A \& Erkan O (1996). Tarım Ekonomisinde Araştırma ve Örnekleme Yöntemleri. Gaziosmanpaşa Üniversitesi, Ziraat Fakültesi Yayınları, No:12, Ders Notları Serisi: 6, Tokat, s.118

Erkuş A, Eliçin A, Özçelik A, Turan A, Tanrıvermiş H \& Gündoğmuş E (1996). Tekirdağ İli Tarım İşletmelerinde İthal ve Kültür Melezi Süt Sığırları İle Üretim Yapan İşletmelerde Süt Siğırcillğ Faaliyetlerinin Karşılaştırmalı Ekonomik Analizi. 
Ziraat Yüksek Mühendisleri Birliği ve Vakfı Yayınları No:14, Ankara

Fidan H (1992). Çorum ilinde sığır yetiştiriciliği yapan tarım işletmelerinin ekonomik analizi ve hayvansal ürünlerin maliyet unsurlarının araştırılması. Yüksek lisans tezi, Ankara Üniversitesi Fen Bilimleri Enstitüsü (Basılmamış), Ankara

Gözener B (2013). TR 83 Bölgesinde sığır besiciliğine yer veren işletmelerin ekonomik analizi ve teknik etkinlik. Doktora tezi, Gaziosmanpaşa Üniversitesi Fen Bilimleri Enstitüsü (Basılmamış), Tokat

Gozener B \& Sayili M (2011). Use of animal wastes in beef cattle farming and environmental considerations. Bulgarian Journal of Agricultural Sciences 17(6): 816-828

Hazneci K (2007). Amasya ili Suluova ilçesinde sı̆̆ır besiciliği yapan işletmelerin etkinlik analizi. Yüksek lisans tezi, Ondokuz Mayıs Üniversitesi Fen Bilimleri Enstitüsü (Basılmamış), Samsun

Kabukçu A (1986). Sığır Besiciliğinin Genel Karakterleri. Hayvancılık Sempozyumu, Cumhuriyet Üniversitesi Yayınları No:16, Emek Matbaası, 5-8 Mayıs, Tokat

Karagölge C (1973). Arazi Tasarruf Şekillerine Göre Erzurum İlindeki Tarım İșletmelerinin Ekonomik Analizi. Atatürk Üniversitesi Ziraat Fakültesi Yayınları: 153, Ankara

Karkacier O (1991). Tokat-Turhal sığır besiciliği işletmelerinin ekonomik analizi. Doktora tezi, Ege Üniversitesi Fen Bilimleri Enstitüsü (Basılmamış), Bornova-İzmir

Karkacier O (2001). Tarım Ekonomisi Alanına İlişkin Fonksiyonel Analizler ve $\mathrm{Bu}$ Analizlerden Çıkartılabilecek Bazı Kantitatif Bulgular. Gaziosmanpaşa Üniversitesi Ziraat Fakültesi Yayınlar1:49, Ders Notları Serisi: 26, Tokat

Kılıç M (1994). Tokat-Merkez ilçede kaynak kullanımı destekleme fonundan yararlanan sığır besiciliği işletmelerinin ekonometrik analizi. Yüksek lisans tezi, Gaziosmanpaşa Üniversitesi Fen Bilimleri Enstitüsü (Basılmamış), Tokat

Kıral T (1993) Ankara İlinde Türkiye Şeker Fabrikaları A.Ş. Besi Bölge Şefliği Tarafından Desteklenen Sı̆̆ır Besiciliği İşletmelerinin Ekonomik Analizi. Ankara Üniversitesi Ziraat Fakültesi Yayınları: 1289, Bilimsel Araştırmalar ve İncelemeler: 715, Ankara
Kıral T, Kasnakoğlu H, Tatlıdil, F F, Fidan H \& Gündoğmuş, E (1999). Tarımsal Ürünler İçin Maliyet Hesaplama Metodolojisi ve Veri Tabanı Rehberi. Tarımsal Ekonomi Araştırma Enstitüsü Yayını, Proje Raporu 1999-13, Yayın No: 37, Ankara

Koyuncu M, Kara Uzun Ş \& Tuncel E (2005). Güney Marmara bölgesel keçicilik işletmelerinin genel durumu ve verim özelliklerinin belirlenmesi üzerine araştırmalar: I. Keçicilik işletmelerinin genel durumu. Tartm Bilimleri Dergisi-Journal of Agricultural Sciences 11(4): 373-378

Oktay A R (1986). Besi Sığırcılığında Verimlilik Ölçümü. MPM Yayın No:345, Ankara

Sayılı M (2001). Amasya ili Suluova ilçesinde sığır besiciliği yapan işletmelerin ekonomik analizi. Doktora tezi, Gaziosmanpaşa Üniversitesi Fen Bilimleri Enstitüsü (Basılmamış), Tokat

Şahin K \& Yılmaz İ H (2008). Van ili Gürpınar ilçesinde yem bitkileri üretimi ve sorunları üzerine bir araştırma. Ankara Üniversitesi Ziraat Fakültesi Tarım Bilimleri Dergisi-Journal of Agricultural Sciences 14(1): 16-21

TÜIKK (2013a). http://www.tuik.gov.tr/HbGetir.do?id=13512\&tb_ $\mathrm{id}=1$

TÜİK (2013b). http://www.tuik.gov.tr/VeriBilgi.do?alt_ $\mathrm{id}=50$

Vural H \& Fidan H (2007). Türkiye'de hayvansal üretim ve hayvancılık işletmelerinin özellikleri. Tarım Ekonomisi Dergisi 13(2): 49-59

Yaylalı M (1994). Mikroiktisat. Cilt: 1, Beta Yayınları, İstanbul

Yücelyiğit E, Zincirlioğlu M \& Yavuz T (1993). Açıkta Serbest Sistem Besicilik. Amerikan Yemlik Tahıl Konseyi Yayını, Ankara

Zoral Y K (1975). Doğu Anadolu'nun Tarımsal Üretiminde Faktörlerin Verimliliği ve Agregate Üretim Fonksiyonları. Atatürk Üniversitesi Yayınları: 432, Ziraat Fakültesi Yayınları:200, Araştırma Serisi No:128, Sevinç Matbaas1, Ankara

Zoral Y K (1984). Üretim Fonksiyonları. Dokuz Eylül Üniversitesi Mühendislik-Mimarlık Fakültesi, MM/ END-84 EY 052, Mühendislik-Mimarlık Fakültesi Basım Ünitesi, İzmir 